\title{
Recovery Characteristics of GdBCO Superconducting Tape With Cooling Fins and Teflon Coating for Resistive Fault Current Limiter
}

\section{$\operatorname{AUTHOR}(\mathrm{S})$ :}

Shirai, Yasuyuki; Yoneda, Kazuya; Higa, Daisuke; Shiotsu, Masahiro; Honda, Yoshihiro; Isojima, Shigeki

\section{CITATION:}

Shirai, Yasuyuki ...[et al]. Recovery Characteristics of GdBCO Superconducting Tape With Cooling Fins and Teflon Coating for Resistive Fault Current Limiter. IEEE Transactions on Applied Superconductivity 2016, 26(3): 5602404.

\section{ISSUE DATE:}

2016-04

URL:

http://hdl.handle.net/2433/228373

\section{RIGHT:}

(C) 2016 IEEE. Personal use of this material is permitted. Permission from IEEE must be obtained for all other uses, in any current or future media, including reprinting/republishing this material for advertising or promotional purposes, creating new collective works, for resale or redistribution to servers or lists, or reuse of any copyrighted component of this work in other works.; この論文は出版社版でありません。引用の際には出版社版をご確認ご利用ください。; This is not the published version. Please cite only the published version. 


\title{
Recovery Characteristics of GdBCO
} Superconducting Tape with Cooling Fins and Teflon
Coating for Resistive Fault Current Limiter

\author{
Yasuyuki Shirai, Member, IEEE, Kazuya Yoneda, Daisuke Higa, Masahiro Shiotsu, Yoshihiro Honda, Shigeki \\ Isojima
}

\begin{abstract}
Recovery time defined as the time during which the superconducting component recovers to its initial condition after the current limiting operation, is very important to design an SFCL. In this paper, the cooling properties of GdBCO superconducting tape with various types of fins or PTFE (polytetrafluoroethylene:Teflon) coating were investigated. Superconducting tape was heated by current, which was larger than its critical current, in liquid nitrogen. The cooling down speed after the current shut down from film boiling to nonboiling and to the superconducting state was investigated. To clarify the effect of surface condition on the heat transfer characteristics, the superconducting test tapes with various shaped fins or PTFE coating were compared with that without fins/coating. According to the experimental results, it was confirmed that superconducting tape with fins or PTFE coating recovered to the superconducting state faster than that without fins/coating and is hopeful for the cooling design of SFCL.
\end{abstract}

Index Terms - Fault current limiter, Recovery time, Cooling fin, Film boiling

\section{INTRODUCTION}

A TER the fault current limiting operation, the SFCL must be recovered to the superconducting state within a proper time according to a relay operation scheme in a power system. The recovery time defined as the time during which the superconducting component recovers to its initial condition after the current limiting operation, is very important to design an SFCL because the repetitive faults may occur in a real power system.

In the current limiting operation of the resistive type SFCL, the heat generation period is rather short (a few hundred ms), but the peak value of generating heat may be too large to be cooled in the nucleate boiling region of LN2. That means the

Automatically generated dates of receipt and acceptance will be placed here; authors do not produce these dates.

Y. Shirai, is with Graduate School of Energy Science, Kyoto University, Sakyo-ku, Kyoto 606-8501, Japan (email: shirai@energy.kyoto-u.ac.jp)

K. Yoneda, is with Graduate School of Energy Science, Kyoto University, Sakyo-ku, Kyoto 606-8501, Japan (email: yoneda@pe.energy.kyoto-u.ac.jp)

D. Higa, is with Graduate School of Energy Science, Kyoto University, Sakyo-ku, Kyoto 606-8501, Japan (email: yoneda@pe.energy.kyoto-u.ac.jp)

M. Shiotsu, is with Graduate School of Energy Science, Kyoto University, Sakyo-ku, Kyoto 606-8501, Japan (email: shiotsu@pe.energy.kyoto-u.ac.jp)

Y. Honda, is with *Sumitomo Electric Industries, Ltd., 1-1-3, Shimaya, Konohana-ku, Osaka 554-0024, Japan, (email: honda-yoshihiro@sei.co.jp)

S. Isojima, is with *Sumitomo Electric Industries, Ltd., 1-1-3, Shimaya, Konohana-ku, Osaka 554-0024, Japan, (email: isojima-shigeki@sei.co.jp) heat flux at the superconductor surface easily exceeds the critical heat flux and heat transfer phenomena shifts to the film boiling region. Moreover, it was reported that the direct transition phenomena from non-boiling regime to film boiling regime is observed in the transient heat transfer in the pool of liquid nitrogen depending on the surface conditions of the superconductor[1].

Because the recovery time becomes long due to the low heat transfer coefficient of film boiling regime, it is important to promote the nucleate boiling, to prevent the stable vapor film and to back to the nucleate boiling regime as soon as possible after the fault clear.

Heat transfer property between heated metal and LN2 depends on the surface condition of the metal. In addition to increasing the cooling surface area, it is expected that the fins promote the nucleate boiling and prevent from quick jump to film boiling regime.

In the previous research, we investigated the impact of the cooling fins attached on the stainless steel cylindrical heater and stainless steel tape heater on the heat transfer characteristics. We have performed experiments of the transient heat transfer from bare and finned test heaters in a pool of liquid nitrogen, and made clear the effect of the fins on improvement of the heat transfer property [2]. Cooling fins prevent the direct transition from non-boiling to film boiling for a certain range of heating rate and the surface temperature at the transition to the film boiling increases gradually. It is considered that the fins prevent the vapor film spreading over the heated material surface. After heating off, the fins promote to break down the vapor film, so the recovery time from film boiling becomes shorter than that for the bare stainless steel heater.

It was reported coatings of a poor thermal conductor on metallic components may shorten the lengthy cool-down process of cryogenic equipment [3],[4]. PTFE coating is also expected to promote the nucleate boiling and to make vapor film unstable.

In this paper, the cooling properties of GdBCO tape with fins or with PTFE coating were investigated. Superconducting tape was heated by current, which is larger than its critical current and then shut down, in liquid nitrogen.

The cooling down speed after the current shut down back to the superconducting state was investigated. To clarify the effect of the surface conditions on the heat transfer 
characteristics, the superconducting test tapes with various shaped fins or with PTFE coating were compared with that without any fins or coating.

\section{EXPERIMENTAL APPARATUS AND METHOD}

\section{A. Experimental Set-up}

The cryostat, which is of $200 \mathrm{~mm}$ in inner-diameter and 700 $\mathrm{mm}$ in height, can be filled with liquid nitrogen of about 14 liters. The cryostat was always exposed to the atomosphere. So the liquid nitrogen temperature was set to only the liquid nitrogen saturation temperature of $77.35 \mathrm{~K}$.

\section{B. Test Method}

The heating current to the test heater was supplied by a power amplifier which can supply a direct current up to $600 \mathrm{~A}$ at a power level of $21 \mathrm{~kW}$. The input signal of the power amplifier was controlled by a digital computer so that the heat generation rate in the test sample tape agrees with a specified reference function. The output voltages of the bridge circuit, together with the voltage drops across the potential taps of the test tape and across a standard resistance, were amplified and passed to a digital memory system.

The test tape was heated by time function of exponential heating $Q=Q_{0} \exp (t / \tau)$ up to a certain level, and then the heater current was shut off to prevent the superconductor tape from overheating. Immediately after shut off the current, small constant current (about $3 \mathrm{~A}$ ) was supplied to the tape in order to measure the resistance of the test tape. Where $\tau$ is the exponential period, that is, shorter $\tau$ is for rapid transient condition. All experiments were carried out at the pressure of $1 \mathrm{~atm}$. under saturated condition

\section{Test Sample}

Test samples were GdBCO tapes provided by Sumitomo Electric Industries Co., Ltd.. The configurations of the test tapes with fin and without fin are shown in Fig.1. Two types of cooling fins were soldered on the front surface (Ag and GdBCO side) of the tapes and the back side (substrate:SUS side) of the tapes were pasted on a FRP block by stycast. The back side of the test sample was insulated by the block as shown in Fig.2.

In order to investigate the effects of cooling fins for recovery properties from normal state to superconducting state, 4 test samples were prepared. One was bare without any fin (No.1). Another sample was with wavy-shaped fin made of SUS304 on the surface (No.2). The other was with L-shaped fins (number of fins: 15) made of copper on the surface (No.3). The cooling fins were carefully soldered to the heated surface. The thickness of the solder is expected to be a few tens $\mu \mathrm{m}$ but not fixed. Another bare (no-fin) sample was coated by spraying PTFE (No.4). The thickness of PTFE coating is expected to be a few $\mu \mathrm{m}$ but not fixed.

The power leads and the voltage taps were soldered on the sample surface apart from cooling fins.

The specification is listed in TABLE I. The lengths between the current leads are about $114 \sim 117 \mathrm{~mm}$ and those of the voltage taps are about $94 \sim 97 \mathrm{~mm}$. Tap to tap resistance at room temperature is about $20.7 \sim 24.7 \mathrm{~m} \Omega$.

The critical temperature $T_{\mathrm{c}}$ of the samples is $92 \mathrm{~K}$. The thickness of Ag cover is $7.3 \mu \mathrm{m}$ in front side and $1.8 \mu \mathrm{m}$ in back side. That of the HTS substrate is $110 \mu \mathrm{m}$.

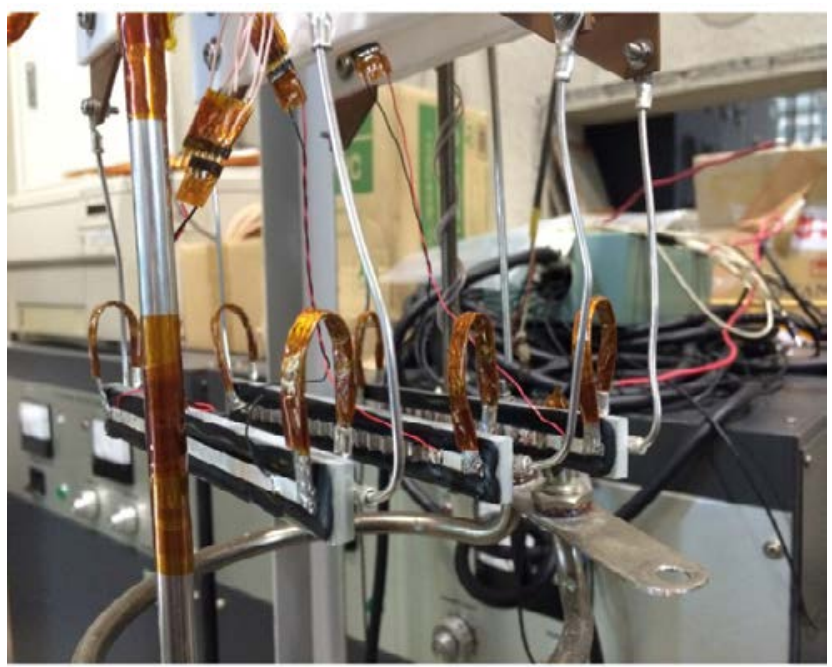

Fig. 1. Photo of the test superconducting tapes with and without fins.
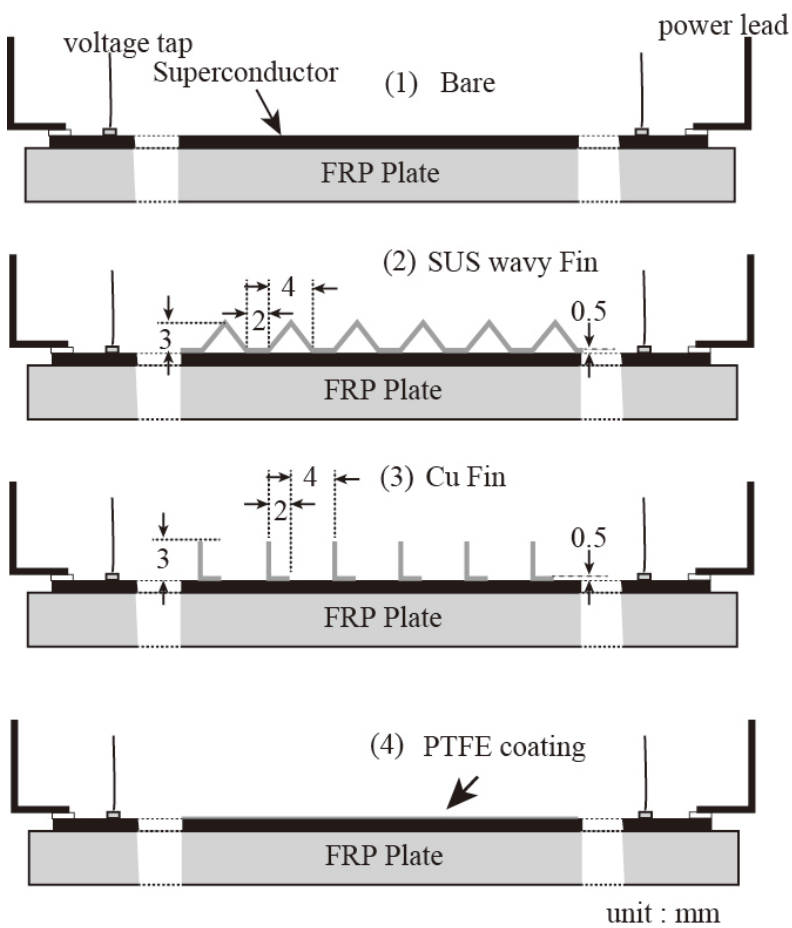

Fig. 2. Schema of test superconducting tapes with and without fins.

TABLE I

TEST SAMPLES

\begin{tabular}{rlrrrrr}
\hline \hline No. & Surface Condition & Lead mm & Tap mm & Ic A & n-value & $\begin{array}{l}\text { Ave-R } \\
\mathrm{m} \Omega / \mathrm{mm}\end{array}$ \\
\hline 1 & No-Fin & 116.5 & 94.8 & 91.3 & 29.3 & 0.244 \\
2 & Wavy-shaped SUS & 116.6 & 99.0 & 94.4 & 22.6 & 0.209 \\
3 & L-shaped Cu & 116.8 & 96.9 & 83.0 & 29.1 & 0.218 \\
4 & No-Fin+PTFE & 116.0 & 96.9 & 96.3 & 24.7 & 0.255 \\
\hline \hline
\end{tabular}




\section{RESULTS AND DISCUSSION}

\section{A. Over-current and recovery test}

One of the experimental results with the bare sample No.1(No-Fin) is shown in Fig. 3. The exponential period $\tau$ was $100 \mathrm{~ms}$. To meet the exponential heating pattern, supplied current for each sample varied as shown in Fig. 3. The superconducting tape turned to normal state at about $95 \mathrm{~A}$, then, the resistance appeared and rose up sharply. When the heat input $Q=R I^{2}$ reached upper limit, that is, the preset point for preventing from burn out, the power supply was shut off at $\mathrm{t}=0.9 \mathrm{~s}$ and recovery process begun.

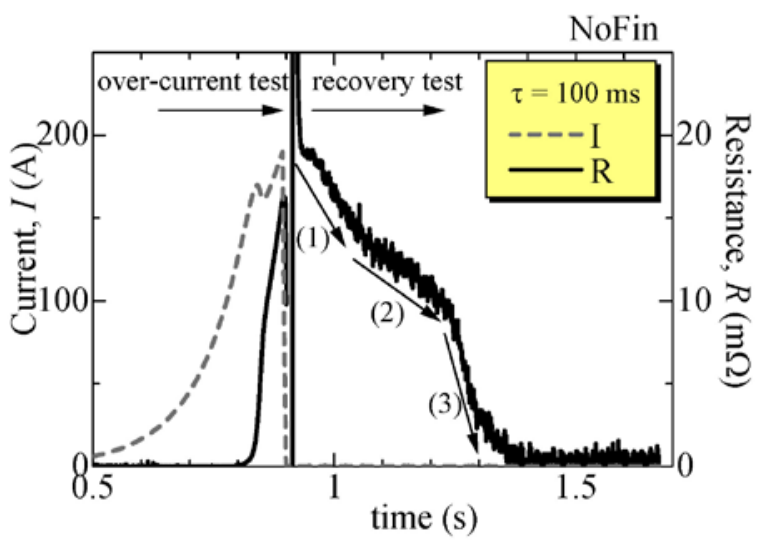

Fig. 3. Supply current and resistance of test sample No.1 (No-Fin) at the over-current and recovery.

We focused the recovery characteristics from normal to superconducting state of the sample after the current shut off. After the supply current shut off, the resistance was measured with another small power supply of $100 \mathrm{~mA}$. The criterion of the zero resistance was set $10 \mu \mathrm{V} / \mathrm{m}$, which was related to test sample resistance of about $1 \mathrm{~m} \Omega$.

As shown in Fig. 3, the resistance $R$ decreased with 3 stages. Section- (1) It decayed with steep slope at the beginning of the recovery from 19 to $13 \mathrm{~m} \Omega$. It is supposed that the vapor film near the power lead and voltage tap was unstable and diminished soon in the first stage.

Section-(2) It decayed with dull slope from 13 to $10 \mathrm{~m} \Omega$. The second stage is corresponding to the stable film boiling regime where the vapor film thoroughly covered over the test tape, therefore the resistance decay was dull.

Section-(3) At last, it dropped down sharply from $10 \mathrm{~m} \Omega$ to zero. The third stage is corresponding to the transition and the nucleate boiling regime, where the vapor film oscillates substantially, shrinks and then diminishes, and the cooling performance is quite good. The break point of the second and third stages is related to the minimum film boiling heat flux.

It took almost $0.48 \mathrm{~s}$ to recover to a fully superconducting state. Sample resistance of $20 \mathrm{~m} \Omega$ is almost the same as that at room temperature.

Fig. 4 shows one of the results of the same experiments as above using sample No. 3 (L-shaped Cu-Fin). The resistance of the sample decreased down to zero with one gradient. There was no clear film boiling regime as observed section (2) in Fig. 3. Even though the peak value of the resistance is similar (19 $\mathrm{m} \Omega$ ), the stable vapor film formation was disturbed by copper fins. It is supposed that the mixture state of the film boiling (between the fins) and the nucleate boiling (around the fins) along the longitudinal direction was existed. The recovery time was reduced to about $0.25 \mathrm{~s}$.

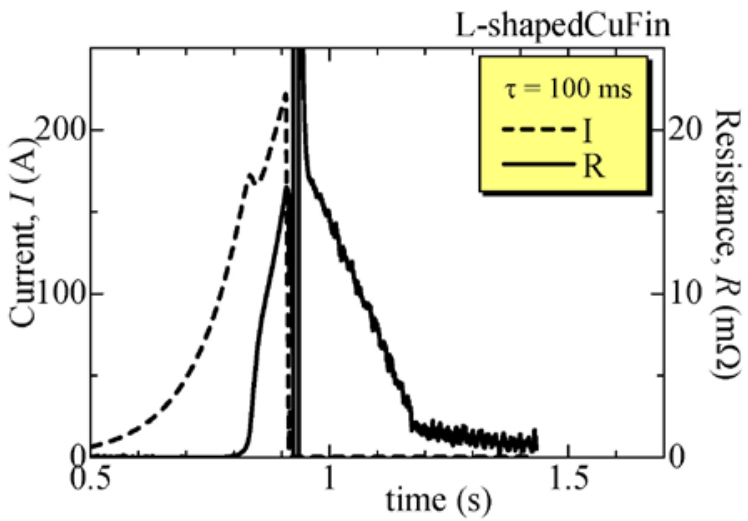

Fig. 4. Supply current and resistance of test sample No.3 (L-shaped Cu-Fin) at the over-current and recovery test.

The same test results for the sample No.4 (PTFE coated) is shown in Fig. 5. Considerable difference exists in transient cool-down of the un-coated (Fig.3) and the coated (Fig.5) samples. The cooling performance is rather similar to that of the sample No.3 (Cu-Fin: Fig. 4.).

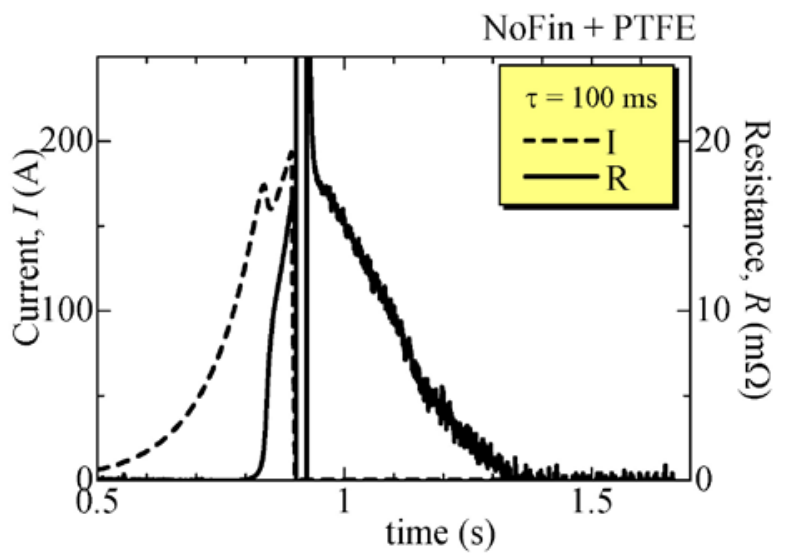

Fig. 5. Supply current and resistance of test sample No.4 (PTFE coating) at the over-current and recovery test.

In the film boiling regime, the vapor-liquid interface and the vapor motion itself are unstable with respect to perturbations of certain wave numbers, so the vapor will be removed from the film and its mass is renewed partially. Since the renewal process is activated by the coatings of a poor thermal conductor, such as PTFE on the heated metal, the vapor film becomes unstable and the minimum film boiling heat flux rises up, so rapid temperature drops and deviation from quasi-steady heat transfer are expected to occur for coated sample.

While the cooling performance was improved by PTFE coating in the film boiling regime, the resistance decay became slow approaching to zero. It is considered that the cooling performance became worse due to the poor thermal conductivity of PTFE in the nucleate boiling regime where the temperature difference between the sample surface and the liquid bulk was small. The recovery time was reduced to about $0.38 \mathrm{~s}$. 


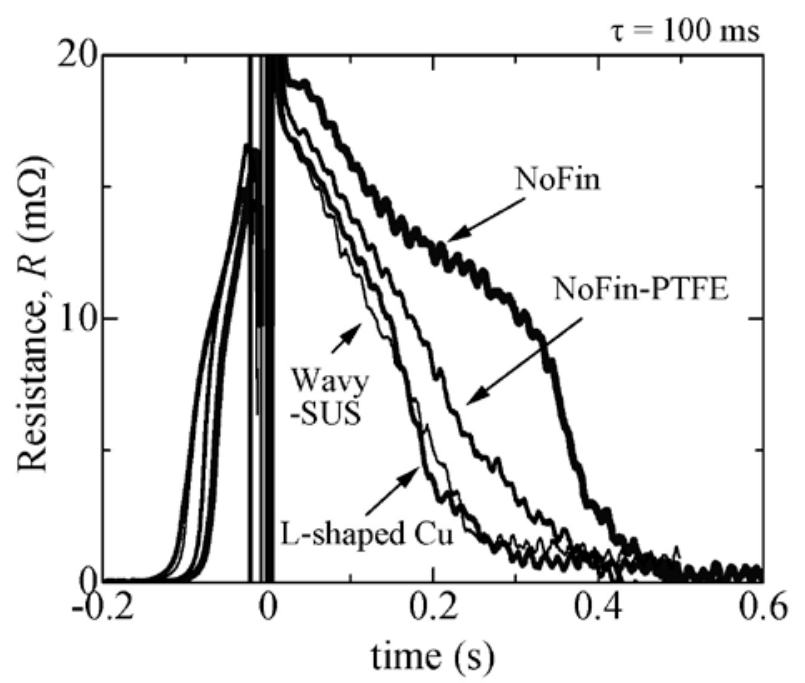

Fig. 6. Resistance appearance of all test samples at the similar heating condition $(\tau=100 \mathrm{~ms})$.

Fig.6 shows resistance appearance of all test samples at the similar heating condition. In order to compare the recovery process, the current shut off time is set time $=0$. The apparent film boiling region was observed only with No-Fin (No.1) sample. The fins and also the PTFE coating successfully made the vapor film unstable and accelerated the cooling process. Wavy-shaped SUS-Fin (No.2) showed similar good cooling performance as that of L-shaped Cu-Fin (No.3).

\section{B. Heating speed and recovery time}

Figs. 7 and 8 show the resistance appearances of the samples with the exponential period $\tau=50$ and $30 \mathrm{~ms}$ of heat input, respectively. The influence on the cooling performance of the heat capacity of materials, mainly FRP plate to which the samples were pasted by epoxy resin, was reduced with shorter heating exponential period.

As shorter the period, the recovery time improvement becomes clear with L-shaped Cu-Fin (No.3) and Wavy-shaped SUS-Fin (No.2).

On the contrary, as shorter the period, the recovery performance became worse with PTFE coating (No.4). While

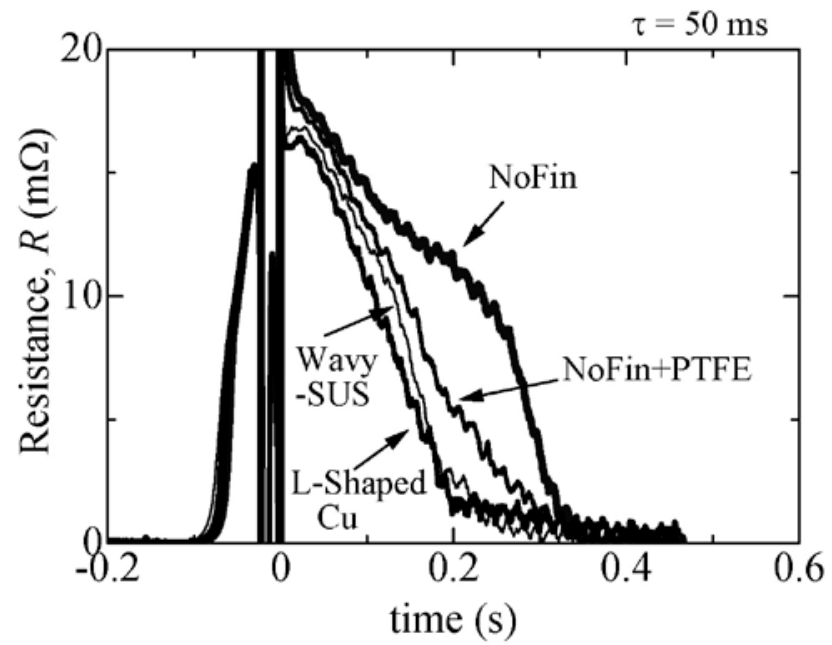

Fig. 7. Resistance appearance of all test samples at the similar heating condition ( $\tau=50 \mathrm{~ms})$.

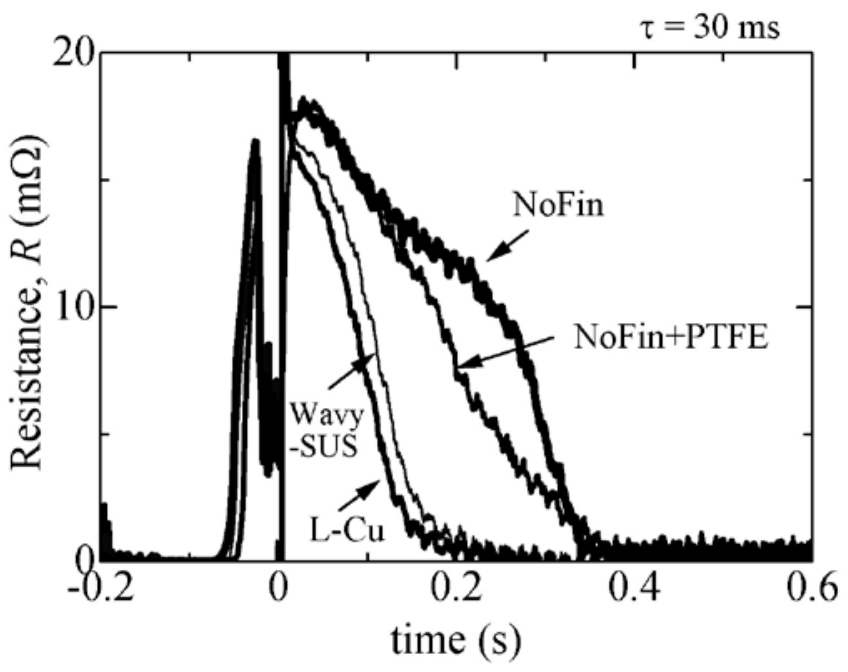

Fig. 8. Resistance appearance of all test samples at the similar heating condition $(\tau=30 \mathrm{~ms})$.

the attached fins divided the vapor film and prevented it from being broad and stable, the PTFE coating just activated the intrinsic instability of the vapor film. It is considered that the cooling improvement by the PTFE coating clearly appears in quasi-static cooing condition but not in transient state.

\section{CONCLUSION}

The cooling properties of GdBCO superconducting tape with various types of fins or PTFE coating were investigated by the experiments using short sample tapes with and without fins or coating. The resistance appearance of the samples was observed at the single shot over-current (exponential heat input and shut off). The recovery performance was evaluated by the resistance decreasing characteristics of each sample after the heat input.

Cooling property improvement was confirmed especially in the fully developed film boiling regime. While the film boiling regime was clearly observed with bare (No-Fin) sample, but was not with any types of fins and also PTFE coating. Stable vapor film was disturbed by the fins or coating and then, the cooling performance was improved. This effect of each fin/coating was different with the heating speed. The L-shaped Copper fin showed the best cooling performance among all.

\section{REFERENCES}

[1] Sakurai, A., Shiotsu, M., and Hata, K., "Boiling Heat Transfer from a Horizontal Cylinder in Liquid Nitrogen", Heat Transfer and Superconducting Magnetic Energy Storage, ed. by J.P. Kelley and M.J. Superczynski, ASME Publication, HTD-Vol.211, pp.7-18, 1992.

[2] H. Fujisaka, Y. Shirai, M. Shiotsu, K. Hasegawa, S. Isojima, K. Noguchi, K. Matsubara, "Heat transfer property of cylindrical bar with various surface shapes in liquid nitrogen”, Proceedings of ICEC24-ICMC2012, pp.51-54, 2012, ISBN 978-4-9906959-0-3

[3] C.W.Cowley, W.J.Timson and J.A.Sawdye, "A method of improving heat transfer to a cryogenic fluid", Adv. in Cryogenic Engineering, Prenum Press, New York, vol.7, p.385, 1962.

[4] J.P.Maddox and T.H.K.Frederking, "Cooldown of insulated metal tubes to cryogenic temperatures", Adv. in Cryogenic Engineering, Prenum Press, New York, vol.11, p.536, 1966. 